\title{
Transdisciplinaridade e educação física escolar: reflexões para o desenvolvimento humano
}

\author{
Marcos Vinícius Guimarães de Paula * \\ João Henrique Suanno **
}

\section{Resumo}

Esse trabalho discute a educação escolar a partir da transdisciplinaridade, destacando suas contribuições para despertar as consciências dos aprendizes, permitindo-lhes atingir novos níveis de realidade e percepção para a vida. Reflete a respeito da relevância da transdisciplinaridade na formação humana do ser aprendente. O trabalho também problematiza a disciplina de Educação Física Escolar sob o olhar da transdisciplinaridade, a fim de colaborar na formação de seres que exerçam uma cidadania planetária, sendo conscientes de suas ações no mundo e sensíveis à vida. Além disso, apresenta a pesquisa qualitativa desenvolvida por meio de um estudo de caso sobre as práticas pedagógicas dos professores do Grupo de Estudos em Educação Física Escolar da rede municipal de ensino de Anápolis-Go (GETEFE). Na pesquisa em destaque, os dados foram coletados por meio de um questionário de auto-percepção e pelas observações das aulas dos professores envolvidos. No total, foram observadas trinta e seis aulas durante os meses de Março, Abril e Maio do ano de 2015. Em relação aos resultados, foi verificado que as práticas pedagógicas dos professores do Grupo GETEFE se aproximaram da proposta da transdisciplinaridade, visto que abarcaram as categorias de análise da pesquisa descritas por Moraes (2010), que são: a contextualização, a criatividade, a dialogicidade, a subjetividade, a flexibilidade, a ecologia da ação, a cooperação, a multireferencialidade, a afetividade e a diversidade. Sendo assim, observou-se que as ações pedagógicas dos professores do GETEFE contribuem para o desenvolvimento humano do aprendiz. Deste modo, o trabalho vislumbra e defende uma Educação Física Escolar que coopere para humanescer.

Palavras-chave: Transdisciplinaridade. Educação Física Escolar. Prática Pedagógica. Desenvolvimento humano.

\footnotetext{
Mestre em Educação, Linguagem e Tecnologias pelo Mestrado Interdisciplinar em Educação, Linguagem e Tecnologias, da Universidade Estadual de Goiás (UEG), orientado pelo prof. Dr. João Henrique Suanno. Bolsista CAPES/ FAPEG, edital n06/2014. E-mail: marcosviniciusguimaraesdepaula@outlook. com

** Doutor em Educação pela Universidade Católica de Brasília - UCB/DF. Pós-Doutor em Educação pela Universidade de Barcelona - UB/ES. Mestre em Educação pela Pontifícia Universidade Católica de Goiás - PUC/GO. Psicólogo - PUC/GO. Psicopedagogo - PUC/ GO. Professor titular da Universidade Estadual de Goiás. Professor do Programa de Pós-Graduação Stricto Sensu Mestrado Interdisciplinar em Educação, Linguagem e Tecnologias - MIELT/UEG. Membro da Rede Internacional de Escolas Criativas - RIEC. Membro do Grupo de Pesquisa Ecologia dos Saberes e Transdisciplinaridade - ECOTRANSD/ CNPq. E-mail: suanno@uol.com.br
} 


\title{
Transdisciplinarity and school physical education: reflections for human development
}

\begin{abstract}
This paper discusses the education from the transdisciplinary, highlighting their contributions to arouse the learner's consciousness, allowing them to reach new levels of reality and perception for life. Reflects on the relevance of transdisciplinary in the human formation of the learner. The paper also discusses the discipline of Physical Education under the gaze of transdisciplinarity in order to collaborate in the formation of beings engaged in a planetary citizenship, being aware of their actions in the world and sensitive to life. Moreover, it presents qualitative research developed through a case study on the pedagogical practices of teachers of the Study Group on School Physical Education municipal Anápolis-Go teaching (GETEFE). Featured in research, data were collected through a self-perception questionnaire and the observations of the classes of the teachers involved. In total, thirty-six lessons were observed during the months of March, April and May 2015. Regarding the results, it was found that the pedagogical practices of teachers GETEFE Group approached the proposal transdisciplinary, as encompassed the categories of analysis of the research described by Moraes (2010), which are: the context, creativity, dialogical, subjectivity, flexibility, ecology action, cooperation, multi-referentiality, affectivity and diversity. Thus, it was observed that the pedagogical actions GETEFE Teachers contribute to the human development of the learner. Thus, the work presents and defense one physical education cooperate the human development.

Keywords: Transdisciplinarity. School Physical Education. Teaching Practice. Human development.

Como educadores, necessitamos começar a praticar uma ética da e para a vida capaz de reintegrar o cosmo, a matéria, o ser humano e a vida, no sentido de resgatar o espírito de solidariedade, de respeito, de gratidão e de reverência pela vida e por todos aqueles que compartilham nosso destino comum. [...] Daí a importância da transdisciplinaridade nutrida por uma visão complexa da realidade como atitude epistemológica, como princípio e como metodologia aberta de construção do conhecimento, como ferramenta capaz de assegurar o espaço de interconexão disciplinar, de uma educação intercrítica e intercultural, nutrida por uma pluralidade de olhares, linguagens, compreensões e percepções da realidade que destroem todo e qualquer dogmatismo, fundamentalismo e pensamento unívoco. Algo que nos ajuda a compreender não só que o ser humano, em sua multidimensionalidade, escapa a todo recorte de natureza disciplinar, mas também que a educação como ação transformadora das diversas dimensões constitutivas da vida, acontece a partir da integração do que ocorre nos mais diferentes
\end{abstract}


níveis de materialidade do objeto, seja ele de natureza física, biológica, social, seja de natureza cultural, psicológica e espiritual. (MORAES, 2015, p. 30-31).

\section{Introdução}

Com base nessa epígrafe, o presente trabalho discorre sobre a transdisciplinaridade e suas possíveis contribuições para o desenvolvimento humano por meio da colaboração na formação de seres conscientes de suas ações para consigo mesmo, com o outro, com o planeta e com a vida, isto é, seres capazes de atingir novos níveis de realidade a partir da reforma do seu pensamento.

Além disso, trata da disciplina de Educação Física para além da domestificação e manipulação dos corpos humanos, pensando-a a partir da transdisciplinaridade, que por sua vez a conecta com as necessidades educacionais contemporâneas, valorizando o afeto, a diversidade, a consciência ambiental, valores como respeito e solidariedade, as emoções, dentre outros.

Retrata ainda o estudo de caso desenvolvido com base nas práticas pedagógicas dos professores do Grupo de Estudos em Educação Física Escolar da rede municipal de ensino de Anápolis-GO (GETEFE), sendo apresentados os objetivos da pesquisa, seu problema científico e seus resultados. Por fim, são feitas algumas considerações críticas em relação às ações pedagógicas desenvolvidas pelos professores do Grupo de Estudos pesquisado.

\section{A respeito da transdisciplinaridade}

De acordo com Alves (2014), as ideias de Descartes contribuíram para a construção nos séculos XVII e XVIII do pensamento cartesiano e para sua disseminação, que reflete até os dias atuais na visão de ciência, mundo e ser humano.

O paradigma cartesiano, útil no momento histórico dos séculos supracitados, é pautado no empirismo, no princípio causa-efeito e no determinismo, que acabam por refletir na fragmentação do conhecimento, do entendimento do que é o homem e a vida. Super valorizava-se, e ainda se super estima a racionalização e a quantificação, enquanto que a subjetividade, a cultura, o sagrado e o aspecto qualitativo em ciência eram desconsiderados. Aqui, a ênfase dada era para uma ciência racional, na qual o corpo era uma verdadeira máquina, como discorre Alves (2014): 
Separou-se o ser humano da natureza e de sua essência. Homem/mulher e natureza passaram a ser concebidos e compreendidos como máquinas, com seus mecanismos passíveis de quantificação, de manipulação e de reprodução, podendo ser divididos, desmontados e montados ao bel prazer. Assim, abriram-se crateras entre o ser e o si mesmo, entre o ser, o outro e a natureza. (p.185)

Nessa direção, a transdisciplinaridade e o pensamento complexo surgem como proposta para repensar a visão cartesiana, apontando para a ciência as interconexões, o saber complexo, que é tecido junto; o ser humano integral, formado por corpo, mente, razão, emoção, sagrado, cultura, isto é, um ser multidimensional. Além disso, destaca a subjetividade do humano e, com ela, o afeto, a emoção e sua relação e conexão como o mundo-planeta em que vivemos. Assim sendo, pensando na relação com a escola, Machado, Nascimento e Leite (2014) entendem que:

Nos dias de hoje, é possível perceber que o modelo cartesiano, linear e determinista, presente no cotidiano da escola, já não consegue explicar essas aceleradas transformações pelas quais passam as sociedades, pois apesar de ser necessário para as práticas da vida mecânica, não consegue resolver problemas humanos que são constituídos de emoções e sentimentos. (p. 212)

Diferentemente do cartesiano, a proposta da transdisciplinaridade juntamente com o pensamento complexo, tem "consciência de que não existe um ser bipartido, dividido em cabeça, tronco e membros, mas sim um ser humano complexo, nutrido pela afetividade, pela emoção e cognição, com suas partes inter-relacionadas." (ALVES, 2014, p. 185). Dessa maneira, de acordo com Moraes e Torre (2004), cabe destacar ainda que:

Hoje, já não é possível, para nós educadores, ignorarmos as implicações epistemológicas do arcabouço científico que envolve os conceitos de intersubjetividade, auto-organização, complexidade, desordem, indeterminância, dinâmica não-linear que caracterizam os sistemas vivos. (p. 35)

Nesse pensar, o presente trabalho reflete a respeito da transdisciplinaridade e do pensamento complexo, lançando um novo olhar para a vida, para a sociedade, para o ser humano e, especificamente, para a educação escolar.

A fim de buscar conceituar a transdisciplinaridade, faz-se necessário a diferenciação de outros conceitos que se mostram relevantes para a compreensão das suas 
especificidades, como a disciplinaridade, a pluridisciplinaridade, a multidisciplinaridade e a interdisciplinaridade

De acordo com Fazenda (1979), a disciplinaridade consiste na organização do processo de ensino em disciplinas que tratam de conhecimentos especializados, representando fragmentos da realidade. É o que comumente acontece em muitas escolas, nas quais o currículo escolar está organizado com as disciplinas desarticuladas, cada uma com seu saber específico, sem estabelecer conexões com os demais conhecimentos.

A respeito da multi e da pluridisciplinaridade, aponta-se que a primeira referese a "justaposição de disciplinas diversas desprovidas de relação aparente entre elas" (FAZENDA, 1979, p. 27), enquanto que a segunda é a "justaposição de disciplinas mais ou menos vizinhas nos domínios do conhecimento" (FAZENDA, 1979, p. 27). Assim, vê-se que a pluridisciplinaridade consiste na interação das várias disciplinas que estabelecem alguma relação entre si, diferentemente da multidisciplinaridade, que não apresenta elo entre as disciplinas.

Assim, um espaço multidisciplinar é formado por disciplinas de diversas áreas do conhecimento, sejam exatas, humanas, biológicas e etc. Nesse espaço, cada disciplina funciona como um departamento que não se relaciona com os outros departamentos relativos às demais disciplinas, ou seja, cada disciplina fica na sua caixa disciplinar, no seu cativeiro, em sua gaiola. Diferentemente, um espaço pluridisciplinar vai além do multi, pois nele as disciplinas se organizam de acordo com suas proximidades. Por exemplo, a química, a biologia e a física formam um espaço pluridisciplinar, uma vez que tem seus objetos de estudos relacionados. Contudo, na pluridisciplinaridade as disciplinas não se relacionam, ou seja, não se juntam para explicar o conhecimento, apenas estão próximas por serem vizinhas nos domínios do conhecimento.

No que tange à interdisciplinaridade, pode-se dizer que corresponde a "interação entre duas ou mais disciplinas na busca da superação da fragmentação das disciplinas" (SUANNO, M.V.R., 2014, p. 100). Nesse sentido, a interdisciplinaridade trata da inter-relação das disciplinas do currículo, objetivando conectar os saberes. Para Suanno, M.V.R. (2014), a interdisciplinaridade está na:

Coordenação, cooperação e integração entre disciplinas, suas especificidades e seus domínios lingüísticos, acerca de uma temática em comum que demanda diálogo, abertura e atitude colaborativa dos sujeitos no ato de investigar e conhecer juntos. Cada sujeito precisa ter domínio profundo da sua disciplina de estudo para que possa contribuir na construção de um olhar interdisciplinar sobre a temática investigada. (p.101) 
Entende-se, portanto, que a interdisciplinaridade é a ligação das disciplinas, cada uma dando a sua contribuição como parte e também como todo para a construção do saber. A interdisciplinaridade pressupõe a interconexão das disciplinas. Isso não significa dizer que cada uma contribui com uma parte ou um momento, mas pelo contrário, na interdisciplinaridade o objeto de estudo é explicado pela interação das disciplinas.

Já a transdisciplinaridade é entendida como “ao que está ao mesmo tempo entre as disciplinas, através das diferentes disciplinas e além de toda a disciplina" (NICOLESCU, 1997, p. 5). Ou seja, é a interação das disciplinas, para se ir além delas, com a finalidade de uma postura humanizada diante da vida, por meio de novos níveis de realidade e de consciência. Assim, de acordo com Suanno, M. V. R. (2015), a transdisciplinaridade tem o desafio de:

Promover a reforma do pensamento e favorecer a metamorfose da sociedade, a fim de produzir transformações nas relações entre ser humano/conhecimento/cultura/natureza. Visa ser uma via de transformação e de autotransformação orientada para o conhecimento e para a criação de nova arte de viver e um novo sentido para a vida.

Pode-se compreender também a transdisciplinaridade como outra forma de se pensar, valorizando a subjetividade, a emoção e o espiritual, ou seja, para além de um olhar lógico, racional e cartesiano. Conforme Moraes (2014), a transdisciplinaridade

Implica uma atitude do espírito humano ao vivenciar um processo que envolve uma lógica diferente, uma maneira complexa de pensar a realidade, uma percepção mais apurada dos fenômenos, a partir do reconhecimento da existência de diferentes níveis de realidade do objeto. Uma atitude que envolve curiosidade, reciprocidade, intuição de possíveis relações existentes entre eventos, coisas, processos e fenômenos, relações que normalmente escapam à observação e ao senso comum. (p. 34)

Batalloso (2014) em suas reflexões humanas e sensíveis, discorre que a transdisciplinaridade é um caminho possível e não um mero discurso idealizado, ou ainda, nas palavras do próprio autor, não é um Olimpo inacessível (BATALLOSO, 2014), isto é, não é um lugar utópico e inalcançável. Destaca também que a transdisciplinaridade é uma outra forma de abordar a existência humana e a construção do conhecimento na educação. Desse modo, Batalloso (2014, tradução nossa) relata: 


\begin{abstract}
A transdisciplinaridade não é uma nova disciplina, nem muito menos uma nova ciência, mas uma forma diferente de abordar a existência humana, a construção do conhecimento e sobre toda a educação. Uma nova forma que leva em conta a importância dos contextos e nossa indissolúvel vinculação e pertencimento a uma mesma pátria comum que é nosso planeta, como nossa própria condição humana que é, ao mesmo tempo, dionisíaco e apolíneo. (p. 44)
\end{abstract}

Nesse mesmo raciocínio, Suanno, M. V. R. (2015), contribui na reflexão a respeito da trandisciplinaridade, dizendo que ela:

Busca a abertura das disciplinas àquilo que as atravessa e as ultrapassa, não propõe que se abandone as disciplinas, ou que se abandone os processos de ensino. Propõe-se que os contextos educativos, com rigor, abertura e tolerância, busquem religar, globalizar, enfim, transdisciplinarizar os conhecimentos, os saberes, as emoções. Possibilitando a construção de uma nova percepção da realidade, oportunizando a ampliação da consciência e desenvolvendo, assim, o cognitivo, o afetivo, o imaginativo, ampliando o compromisso dos sujeitos com a própria vida, com a vida coletiva, com o bem comum e com a construção de uma consciência planetária. (p. 115)

Entende-se ainda que a transdisciplinaridade representa uma nova via para a educação escolar e também para a vida, permitindo que sejam atingidos novos níveis de realidade e de percepção por meio do despertar das consciências do seres aprendentes, que por sua vez contribuirá para a compreensão da condição humana que está em constante processo de crescimento e transformação. A transdisciplinaridade colabora na formação de seres críticos, ativos socialmente e sensíveis a tudo que os rodeia, isto é, seres protagonistas sociais.

Nessa perspectiva, esse trabalho apresenta a seguir a pesquisa de mestrado realizada com os professores do Grupo de Estudos em Educação Física Escolar da rede municipal de ensino de Anápolis-Go (GETEFE), realizada dentro do Programa de Pós-graduação Stricto Sensu Mestrado interdisciplinar em Educação, Linguagem e Tecnologias da Universidade Estadual de Goiás (UEG). Vale mencionar que a referida pesquisa foi financiada pela FAPEG no âmbito do acordo com a CAPES, conforme edital $n^{\circ} 06 / 2014$. 
A Educação Física Escolar sob a ótica da transdisciplinaridade: um estudo de caso

A transdisciplinaridade permite repensar valores e ações que marcam a sociedade do século XXI, como o individualismo, a competição exacerbada, a ingratidão, a violência, a crise da ética, o esvaziamento da pessoa humana, dentre outros. Consequentemente, acredita-se que ela contribui para polinizar e reverberar aspectos como a cultura de paz, a empatia, a criatividade, a afetividade, a cooperação, a sensibilidade, a consciência ambiental e a solidariedade, para que se possa desconstrir/construir um mundo melhor para se viver.

No que tange especificamente à disciplina de Educação Física, é necessário dizer que a transdisciplinaridade permite compreendê-la para além da domestificação dos corpos humanos. Ora, já não há mais espaço para uma Educação Física na escola sem amor, rígida, disciplinar e militarizada, que acaba por transformar o sujeito aprendente em uma verdadeira máquina de rendimentos que deve atender as exigências físicas e motoras dos seus professores.

Desse modo, a transdisciplinaridade permite pesquisar a Educação Física Escolar numa perspectiva humana "quente", cujo calor é proveniente das relações estabelecidas a partir do amor, da beleza das relações humanas, da poesia da vida, da cooperação como caminho de vida, do afeto e do amor, e também da vontade de contribuir, mesmo que minimamente para a comunidade a que todos formamos, ou seja, a humana.

Nessa direção, esse trabalho destaca a importância de se pesquisar a Educação Física Escolar como componente curricular que tem muito a contribuir na formação humanística do ser. Sendo assim, inicialmente, recorre-se a história da Educação Física para que se possa perceber como era pensada no período de sua gênese.

De acordo com Coletivo de Autores (1992), no final do século XVIII e início do século XIX a Educação Física escolar era marcada pelo paradigma biológico relacionado ao corpo. Entende-se que esse paradigma ainda é forte nos dias atuais, fazendo com que as esferas sociais, culturais, psicológicas e espirituais do sujeito sejam deixadas de lado, negando-se a totalidade e a multireferrencialidade do sujeito humano, contribuindo para que a corporeidade seja esmagada, muitas vezes, em exercícios rígidos e disciplinares.

Acredita-se que essa visão biológica para o corpo ainda marca a área da Educação Física Escolar, revelando a necessidade de repensar sobre sua finalidade no espaço educacional da escola. Para tanto, na pesquisa realizada, os conteúdos da Educação Física Escolar são discutidos sob a perspectiva transdisciplinar, apresentando a discipli- 
na de acordo com uma proposta humanizada, valorizando as relações interpessoais, a relação com o meio ambiente, as emoções, a criatividade, a afetividade, a diversidade, $\mathrm{e}$ demais aspectos importantes para se pensar a sociedade que se almeja ajudar a formar.

Assim sendo, os conteúdos dessa disciplina foram apresentados e discutidos na pesquisa sob o olhar transdisciplinar, destacando: a consciência ambiental para uma cidadania planetária, a violência e o racismo nos estádios de futebol e em espaços de práticas corporais, a discussão sobre a diversidade nas aulas, os jogos cooperativos como exercício de convivência, os conteúdos que trabalham o sentipensar (MORAES e TORRE, 2004), isto é, a relação intrínseca entre razão e emoção, dentre outras possibilidades de intervenção.

Vale destacar que a abordagem da pesquisa desenvolvida foi qualitativa, que "não se propõe testar relações causa e conseqüência entre fenômenos. A pesquisa qualitativa procura entender, interpretar fenômenos sociais inseridos em um contexto". (BORTONI-RICARDO, 2008, p. 34). Além disso, a teoria da complexidade e da transdisciplinaridade foi adotada no que concerne à epistemologia. Optou-se pela complexidade, pois ela é, segundo Moraes e Valente (2008):

Construtivista, interacionista, fundada na intersubjetividade dialógica, geradora de uma base epistemológica complexa, a qual implica aceitação da natureza múltipla e diversa do sujeito e do objeto estudado, envolvendo dinâmica não linear, dialógica, interativa, recursiva e aberta. Resgata a biopsicossociogênese do conhecimento humano. Conhecimento inscrito na corporeidade humana. (p. 16)

Com base nos trabalhos de Gil (1999), Lüdke e André (1986) e Yin (2001), foi realizado um estudo de caso com os professores do Grupo de Estudos em Educação Física da rede municipal de ensino de Anápolis-GO (GETEFE), tendo como problema científico as seguintes indagações: que contribuições os princípios da transdisciplinaridade trazem à prática pedagógica em Educação Física Escolar? A prática pedagógica dos professores do GETEFE se aproxima da proposta da transdisciplinaridade?

A pesquisa apresentou como objetivo geral: analisar se a prática pedagógica dos professores do GETEFE se aproximava ou não dos princípios da transdisciplinaridade. E como objetivos específicos: averiguar se as atitudes dos professores do GETEFE abarcavam elementos que compõe a transdisciplinaridade e identificar possíveis práticas pedagógicas transdisciplinares no trabalho dos professores do GETEFE.

Em relação à técnica de coleta de dados foram realizadas observações das aulas do professores do Grupo GETEFE, sendo o grau de participação do pesquisador defi- 
nido por Lüdke e André (1986) como observador como participante. Cabe dizer ainda que o pesquisador fez uso de um diário de pesquisa na fase das observações das aulas.

A pesquisa foi realizada com quatro professores do GETEFE. Foram observadas nove aulas de cada professor em três dias diferentes, com exceção apenas de um dos professores, que teve suas nove aulas observadas em dois dias, em função da distância da escola onde leciona que fica no distrito de Souzânia, distante aproximadamente $30 \mathrm{~km}$ da cidade de Anápolis. No total, trinta e seis aulas foram observadas ao longo da pesquisa durante os meses de Março, Abril e Maio de 2015. Como forma de obtenção de dados, também foi aplicado aos professores do GETEFE um questionário fechado de auto-percepção, no qual os professores se auto-avaliaram quanto a suas práticas pedagógicas.

Para a etapa da análise de dados, foram estabelecidas, conforme Moraes (2010), as seguintes categorias de análise: contextualização, criatividade, subjetividade, cooperação, multiferencialidade, afetividade, dialogicidade, flexibilidade, ecologia da ação e diversidade.

Com base nas aulas observadas e nos dados obtidos pelo questionário pode-se afirmar que as práticas pedagógicas dos professores do GETEFE se aproximaram da proposta da transdisciplinaridade, uma vez que foram verificadas práticas pedagógicas que valorizaram o diálogo, a contextualização, as emoções, a diversidade, a cooperação, a afetividade, a criatividade, dentre outros aspectos que contemplam as categorias de análise da pesquisa.

A dialogicidade se fez presente na prática pedagógica dos professores do GETEFE. Entende-se que o diálogo é fundamental na construção do conhecimento. O aluno precisa ser ouvido, pois suas contribuições são significativas, tornando-o sujeito ativo na aprendizagem. Já não cabe mais uma educação unidirecional, na qual apenas o professor profere verdades absolutas e os educandos apenas as assimilam.

Portanto, pode-se afirmar que é por meio do diálogo que professor e alunos se completam e se ajudam para a construção dos saberes. Moares (2014) faz um alerta importante sobre o tema:

Em realidade, continuamos ignorando a construção dos saberes das pessoas comuns. Não prestamos atenção a elas. Não prestamos atenção aos nossos alunos e aos saberes da tradição. Para muitos, suas opiniões, expressões e informações são referências cognitivas sem importância, embora reconheçamos interiormente que estão impregnadas de sabedoria e de experiências vividas. (p. 27) 
A contextualização também foi encontrada nas práticas pedagógicas dos professores pesquisados, fazendo com que os conteúdos trabalhados apresentassem significado para o aprendiz (BATALLOSO, 2014). De acordo com Moraes (2010), a contextualização é uma importante característica da transdisciplinaridade, uma vez que reflete em uma aprendizagem com sentido para quem aprende. Sendo assim, concorda-se com a autora:

Cada professor ou cada estudante em formação tem que contextualizar os conhecimentos para que a aprendizagem possa ter sentidos. Contextualizar, a partir de processos individuais e coletivos da construção do conhecimento, o que significa dar vida ao conhecimento construído, tornando-o significativo e pertinente, algo que tenha sentido para os que o constroem. (p. 106, tradução nossa)

Cabe considerar ainda que a contextualização permite que o aluno seja reentroduzido no processo de construção dos saberes, pois ao se contextualizar com a vida, com a cultura e a com a rotina do ser aprendente, ele torna-se coautor desse processo. Assim, a contextualização está relacionada com o princípio da reintrodução do sujeito cognoscente, no qual "o sujeito, autor de sua história e coautor de construções coletivas, é resgatado no processo de construção do conhecimento." (MORAES, 2015, p. 57).

As emoções dos alunos também foram contempladas nas práticas pedagógicas dos professores do GETEFE, destacando a multireferencialidade do educando e tornando a escola como espaço para se educar com amor e para o amor (MORAES, 2003). A valorização da diversidade também foi verificada nas ações pedagógicas dos professores do Grupo GETEFE, possibilitando que os alunos transcendessem para novos níveis de percepção para o outro (MATURANA, 2000).

Foi verificado também o trabalho com a cooperação nas intervenções pedagógicas dos professores envolvidos na pesquisa, destacando a possibilidade da convivência harmoniosa como caminho de vida. A cooperação revela-se como um elemento transdisciplinar importante, que trás a tona a figura do outro como ser fundamental para a existência do eu. A cooperação aponta que o ser humano se realiza no encontro com seus outros, de tal forma que ninguém é alguém sozinho, pois ninguém é uma ilha (ALVES, 2014). Sendo assim, a cooperação possibilita apreender que os seres humanos são co-autores da história da vida, estando interligados, mesmo que inconscientemente.

Ainda foram detectadas ao longo das observações, a afetividade nas relações entre professor e alunos, tornando o espaço escolar acolhedor e a adversidade como 
fonte criadora de novas possibilidades (TORRE, 2011), ou seja, a adversidade como fonte para a criatividade.

Sobre a criatividade é relevante compreender que não se pode idealizá -la, acreditando que ela se desenvolve apenas em espaços propícios, com bons e variados materiais. A criatividade ocorre também em meio ao caos e à crise, ou seja, há um grande potencial criativo em situações adversas. Nesse sentido, Torre (2011, p. 47) apresenta o conceito de criatividade a partir de um novo olhar: "como emergência do potencial transformador que surge em situações de adversidade, carência ou diversidade relegada." Vê-se, então, que em meio à adversidade, a criatividade pode se materializar. É o que Torre (2011) nomeia de adversidade criadora.

Dessa forma, pretendemos sair do estabelecido, do que temos entendido como verdadeiro e correto, buscando na escuridão identificar algo que a escassa luz da consciência positiva nos impede de ver. Para isso, é preciso acender outra consciência que nos possibilita entender que as situações de adversidade, dor e carência são oportunidades e fontes de evolução e transformação. (p. 56)

Essa compreensão da adversidade criadora é essencial na escola, sobretudo, na escola pública, onde há carências de materiais e recursos. Nesse aspecto, o trabalho desenvolvido pelos professores do GETEFE se destacou, pois os recursos didáticos para as aulas são poucos e com baixa qualidade.

Acredita-se que ao enfrentar às adversidades da realidade, os professores do GETEFE agiram com outra consciência, vendo na crise novos caminhos e novas possibilidades de ação. Entretanto, em relação à criatividade, é preciso dizer que foram poucos os momentos em que os professores pesquisados possibilitaram que os alunos criassem durante as aulas. Percebeu-se que os professores já traziam tudo pronto para os alunos, não os estimulando para criar.

Entende-se que a criatividade está intimamente ligada à autoria, conforme chama a atenção Amaral (2011), discorrendo que a autoria é essencial para que ocorra aprendizagem criativa, pois o indivíduo se percebe como sujeito do processo de aprendizagem e se reconhece como autor de seu trabalho, sendo valorizada sua autonomia e sua singularidade.

Dessa forma, pelo que já foi exposto, avalia-se que as ações pedagógicas desenvolvidas pelos professores do GETEFE contribuem para o desenvolvimento humano dos alunos, ou seja, a prática pedagógica desses professores ajuda a hu- 
manescer, que segundo Moraes (2014), é explorar o melhor do humano no próprio humano.

As práticas pedagógicas dos professores do GETEFE refletem um avanço para área da Educação Física Escolar, pois durante muito tempo os objetivos dessa disciplina estavam vinculados única e exclusivamente à saúde e à aptidão física. Com a pesquisa realizada com o Grupo GETEFE foi possível verificar a importância que essa disciplina tem na formação humana do ser.

Entretanto, durante as aulas acompanhadas no desenvolvimento da pesquisa foi possível perceber que ainda há vestígios de uma formação positivista dos professores pesquisados. É necessário pontuar que as influências técnicas/positivistas ainda são muito fortes na formação do professor de Educação Física, revelando a necessidade de uma formação acadêmica mais humana, que abarque o psicológico, o social e o espiritual do professor em formação. Nesse pensar, é preciso discutir a respeito da formação docente na perspectiva complexa e transdisciplinar. A esse respeito, Nicolescu (1997) afirma que a universidade é um importante espaço de transformação humana. Para ele:

\begin{abstract}
A universidade é o lugar privilegiado para uma formação apropriada às exigências de nosso tempo; além disso, é o pivô da educação destinada às crianças e aos adolescentes. A universidade poderá, portanto, tornar-se o lugar ideal para o aprendizado da atitude transcultural, transreligiosa, transpolítica e transnacional, para o diálogo entre a arte e a ciência, eixo da reunificação entre a cultura científica e a cultura artística. A Universidade renovada será o lugar de um novo tipo de humanismo. (p. 08)
\end{abstract}

Em suma, pode-se afirmar que o trabalho desenvolvido pelos professores do Grupo GETEFE contemplaram elementos que compõem a transdisciplinaridade, contribuindo para formação humana dos educandos, permitindo-lhes atingir novos níveis de realidade e de compreensão para a vida.

\title{
Considerações Finais
}

A transdisciplinaridade revela um olhar mais humano para a educação, tão necessário em nossa sociedade caracterizada pela violência da desumanização e pela barbárie da racionalização, como bem nos disse Edgar Morin. É uma forma diferente de tratar o aluno, compreendendo-o em sua multidimensionalidade, isto é, sujeito histórico, social, cultural, emotivo, psicológico e espiritual. Contribui 
na formação de um indivíduo integral, e não mais um ser apenas racional, cujas emoções são esquecidas.

Além disso, colabora naquilo que Edgar Morin tem chamado de reforma do pensamento humano. Acredita-se que uma vez reformado o pensamento, as consciências são despertadas e ativadas, e aos poucos, vai se criando uma grande rede complexa e transdisciplinar, que por sua vez gera bons frutos: cidadãos comprometidos com um espaço social mais fraterno, solidário e amoroso. Cidadãos que aprendem a cuidar de si, dos seus outros, da sua comunidade local e do planeta. Cidadãos que exerçam uma cidadania planetária.

No tocante a Educação Física Escolar, a transdisciplinaridade possibilita refletir na contribuição dessa disciplina no ensino da paz, da solidariedade e do respeito à diversidade. Essa disciplina na escola, juntamente com as demais disciplinas do currículo, pode (e deve!) valorizar o coração dos aprendentes, não visando apenas o rendimento físico e atlético de seus alunos, transformando-os em máquinas, mas explorando sua corporeidade em aulas criativas, com clima prazeroso e afetivo.

Após a realização dessa pesquisa e com base nas reflexões a partir dela, considera-se que a Educação Física Escolar tem contribuição ímpar na humanização do humano e na melhora da nossa vida em nossa Terra.

Urge, portanto, pensar e desenvolver uma prática pedagógica transdisciplinar na Educação Física Escolar. Defende-se, aqui, uma Educação Física que não seja domestificadora dos corpos e controladora das mentes.

Dessa forma, sob a ótica da transdisciplinaridade, pode-se afirmar que essa é a Educação Física Escolar que queremos: uma Educação Física para o desenvolvimento humano, ou seja, uma disciplina de Educação Física que possibilite humanescer por meio de práticas pedagógicas que: valorizem o amor, a multirreferencialidade do sujeito humano e a criatividade; trabalhem a corporeidade e suas emoções; ensinem a paz e a cooperação; ajudem a cuidar de si, do outro e do lar-Terra.

Por fim, Suanno, Paula e Arantes (2015) ajudam a repensar a respeito da prática pedagógica na Educação Física, estabelecendo diálogos possíveis com a transdisciplinaridade. Eles questionam e provocam a refletir:

Por que não se discutir e vivenciar com os alunos a cooperação como forma de jogo? Por que não mostrar um olhar sensível para o outro? Por que não refletir os conteúdos para além das competições exacerbadas que marcam a Educação Física Escolar? Por que não despertar as consciências dos alunos quanto à escassez da água do nosso planeta? Por que não discutir a violência nos estádios que matam cada vez mais e transformam, muitas vezes, 
os jogos em verdadeiros espaços de guerra? Por que não problematizar o respeito às diferenças nas aulas de Educação Física? Por que não contribuir na formação de seres humanos que convivem em espaço harmonioso com a diferença (gordo, magro, baixo, alto, negro, branco, devagar, rápido, fraco, forte)? Por que não propor atividades utilizando as TICs (tecnologias da informação e comunicação) que estimulem a construção do conhecimento? Por que não se pensar uma Educação Física Escolar crítica e humanística? Tais indagações e inquietações vislumbram uma Educação Física dentro de um currículo escolar transdisciplinar, juntamente com as demais disciplinas, rumo à formação de seres humanizados, sensíveis, críticos, reflexivos e conscientes. (p. 94)

\section{Referências}

ALVES, M. D. F. Psicopedagogia e transdisciplinaridade: a sabedoria da diversidade. In: MORAES, Maria Cândida; SUANNO, João Henrique. O pensar complexo na educação: sustentabilidade, transdisciplinaridade e criatividade. Rio de Janeiro: Wak Editora, 2014.

AMARAL, A. L. S. N. do. A constituição da aprendizagem criativa no processo de desenvolvimento da subjetividade. Brasília-DF: UnB, 2011. 250 p. Tese (Doutorado) Programa de Pós-Graduação em Educação, Faculdade de Educação, Universidade de Brasília, Brasília-DF, 2011.

BATALLOSO, J. M. Educación, transdisciplinariedad y pensamiento ecosistémico: uma aproximación a la prática. In: MORAES, Maria Cândida; SUANNO, João Henrique. $O$ pensar complexo na educação: sustentabilidade, transdisciplinaridade e criatividade. Rio de Janeiro: Wak Editora, 2014.

BORTONI-RICARDO, S. M. O professor pesquisador: introdução à pesquisa qualitativa. São Paulo: Parábola, 2008.

COLETIVO DE AUTORES. Metodologia do Ensino de Educação Física. São Paulo: Cortez, 1992.

FAZENDA, I. Integração e interdisciplinaridade no ensino brasileiro: efetividade ou ideologia. São Paulo: Loyola, 1979. 
GIL, A. C. Métodos e técnicas de pesquisa social. 5. ed. São Paulo: Atlas,1999.

LÜDKE, M.; ANDRÉ, M. E. D. A. (orgs.). Pesquisa em educação: abordagens qualitativas. São Paulo: EPU, 1986.

MACHADO, M. J.; NASCIMENTO, Patrícia Limaverde; LEITE, Deliene Lopes. Os operadores cognitivos do pensar complexo na docência universitária: possibilidades e desafios. In: MORAES, Maria Cândida; SUANNO, João Henrique. O pensar complexo na educação: sustentabilidade, transdisciplinaridade e criatividade. Rio de Janeiro: Wak Editora, 2014.

MATURANA, H. O que se observa depende do observador. In: W. I. Thompson (org.). Gaia: Uma teoria do conhecimento. São Paulo: Editora Gaia, 2000.

MORAES, M. C. Educar na biologia do amor e da solidariedade. Petrópolis - RJ: Vozes, 2003.

; TORRE, S. de la. Sentipensar: fundamentos e estratégias para reencantar a educação. Petrópolis - RJ: Vozes, 2004.

; VALENTE, J. A. Como pesquisar em educação a partir da complexidade e da transdisciplinaridade? São Paulo: Paulus, 2008.

Formación docente desde la mirada transdisciplinar. In: PUJOL MAURA, M. A. e TORRE, S. de la. Creatividad y Innovación: enseñar com outra conciencia. Madrid: Editorial Universitas S.A., 2010.

Educação e sustentabilidade: um olhar complexo e transdisciplinar. In: MORAES, Maria Cândida; SUANNO, João Henrique. O pensar complexo na educação: sustentabilidade, transdisciplinaridade e criatividade. Rio de Janeiro: Wak Editora, 2014.

Transdisciplinaridade, criatividade e educação: fundamentos ontológicos e epistemológicos. Colaboração de Juan Miguel Batalloso Navas. Campinas, SP: Papirus, 2015. 
NICOLESCU, B. Projeto CIRET-UNESCO: evolução transdisciplinar da universidade. Bangkok: Chulalongkorn University, 1997. Disponível em: http://www.moodle.fmb. unesp.br/mod/resource/view.php?id=60. Acesso em: 05 abr. 2014.

SUANNO, J. H.; PAULA, M. V. G. de; ARANTES, V. H. de P. O olhar transdisciplinar para a Educação Física Escolar. In: Pinho, Maria José de; SUANNO, Marilza Vanessa Rosa; Suanno, João Henrique. Projetos criativos na prática pedagógica: cantar e encantar a aprendizagem. Goiânia: Editora Espaço Acadêmico, 2015.

SUANNO, M. V. R. Em busca da compreensão do conceito de transdisciplinaridade. In: MORAES, M. C.; SUANNO, J. H. O pensar complexo na educação: sustentabilidade, transdisciplinaridade e criatividade. Rio de Janeiro: Wak Editora, 2014.

Didática e trabalho docente sob a ótica do pensamento complexo e da transdisciplinaridade. 2015. 490 p. Tese de Doutorado em Educação, pelo Programa de PósGraduação Stricto Sensu em Educação, pela Universidade Católica de Brasília - UCB, Brasília-DF, 2015.

TORRE, S. de La. Adversidade e diversidade criadoras: desenvolvendo outra consciência. In: TORRE, S. de la; ZWIEREWICZ, M.; FURLANETTO, E. C. Formação docente e pesquisa transdisciplinar: criar e inovar com outra consciência. Blumenau: Nova Letra, 2011.

YIN, R. K. Estudo de caso. Planejamento e métodos. Porto Alegre: Bookman, 2001.

Recebido em: 16 abril 2016.

Aceito em: 28 abril 2016. 